\title{
La recreación de la materia
}

MARIA DEL PILAR PALOMO

En el invierno zamorano de 1987, acompañados de un grupo de poetas amigos, coincidí con Miguel Fernández en nuestra visita a San Pedro de la Nave. Recuerdo vivamente la emoción de Miguel frente a aquellas piedras labradas hace más de mil años, donde unos anónimos canteros visigodos habían "recreado" la materia, que, transformada en toscas figuras de serpientes o racimos, devenía un sistema de signos cuya simbología iba descodificando ante nosotros el historiador amigo que nos acampanaba. Miguel, entonces, se refirió a su propia poética, de comunicación simbólica, rechazando su presunto hermetismo. Tampoco eran herméticas las piedras seculares de San Pedro de la Nave, cuando se las contemplaba como un sistema de signos, y se meditaba sobre esta contemplación. Volví sobre esta vivencia compartida cuando, pocos años después, leía su reflexión sobre un cuadro de Miró, La masía. Una reflexión puesta en boca -en mente- de Hemingway, que observa en él una delectación en los objetos — "barreño cuba regadera taburete / pozo acequia escalera pellejo / palomar noria periódico..." ${ }^{n}$ - mientras elude los rostros de los seres vivientes. "La exaltación sólo queda en los objetos", y 
apunta, clarividente: "Es indudable que Miró, al pintar este cuadro, sólo buscaba la recreación de la materia, y por ser la existente, la sacralizaba" (1). Y aún tuve que volver sobre esta contemplación-recreación-sacralización de la materia cuando leí la que —creo— fue una de sus últimas entrevistas, aparecida a finales de 1992. En ella se le pedía a Miguel Fernández que sintetizara su poética en cinco líneas y le sobraron cuatro: "El recrear la realidad" (2). La escueta definición podía, sin embargo, ampliarse con unas declaraciones anteriores, a propósito de su célebre poema "El muchacho de chaleco rojo". Todos los amigos y lectores de Miguel Fernández sabíamos de su predilección por este poema, que le oímos recitar en varias ocasiones y que, casi ineludiblemente, figuraba en cuanta selección de poemas propios se le pidiese al autor. "Este poema es para mí emblemático", afirma, y parece, en una lectura superficial de la declaración, que su importancia derivaría de su absoluta originalidad en el momento de su escritura - hacia 1952-, como un poema, inspirado en un cuadro - "Homenaje a Paul Cézanne" - que rompía la estética al uso y se anticipaba en treinta años a imperantes usos culturalistas. Pero el poema es emblemático en la poesía total de Miguel Fernández porque entiendo que es el primero en que, metapoéticamente, evidencia en su obra la traformación de la realidad: la verdad no está en lo referencial contemplado sino en esa otra realidad a la que llegamos por la meditación de lo contemplado. Y la realidad poética está, a su vez, en la contemplación de lo meditado. Una supra-realidad o intra-realidad, de carácter intelectual - $\mathrm{u}$ onírico, como veremos-, que covierte en vida una imagen recreada y que ha podido partir de lo inerte. Un modo, en cierta manera, de resurrección de la materia.

Volvamos sobre el muchacho de Cézanne. Afirma el poeta y -y aquí creo que está el carácter emblemático del poema, no en su aparente, falso y anticipador parnasianismo-, que "surgió de meditar lo contemplado (un cuadro). Se escribió al contemplar lo meditado. ¿̨Hay otra norma?". Y esa contemplación segunda — de la que brota el poema recrea de tal modo la melancolía de la primera realidad —el cuadro—, que, tras la apariencia - la "historia" brota, transfigurada, la persistencia de la vida, como una resurrección: 
"Mas si arañas la tierra

verás que allí debajo está tu hermana viva,

tu nombre, tu familia,

y ese chaleco húmedo por tu sangre, muchacho".

Muchos años después, la contemplación — frescos de la Florida - de lo meditado - la visión de España - le llevará a Miguel Fernández a fusionarse con Goya y pintar con él un mundo nuevo:

“Mi cabeza es la lámpara.

Ya tengo

luces que alumbren las legislaciones:

Pintar, más que lo vivo, lo soñado" (3).

Escribir, más que lo vivo, lo soñado, porque ese sueño contemplativo es lo que, mediante la palabra, confiere eternidad a lo transitorio de la materia y el vivir. Así, en la exacta Poética, de 1975:

"Acontece el suceso y contemplado

se queda ya por siempre.

Ojos que no han de ver,

lo miran si lo inventa.

Pasa la realidad y siempre es otra

pues ya por meditada se transforma.

Y nace el sueño, más real que aquélla.

Si sólo se quedara lo que vemos

tal como así discurre,

sería finitud lo que acontece,

no eterno devenir" (4).

Contemplación —n el alto sentido humanista y renacentista del término- que es meditación, transformacion y, en consecuencia, resurrección: 
ese "eterno devenir" que encierra, en uno de sus sentidos - el que le confirieron los estoicos- el término palingenesia, el retorno periódico y eterno de los acontecimientos, que Miguel Fernández simbolizará en la continua resurrección de la rosa, "nacida de la muerte pura" (5). O palingenesia en la interpretación platónica, en donde ese retorno es el del alma del sabio, retornando al mundo de las Ideas, como eterno contemplador de la esencia. Como el poeta, conocedor supremo de esa otra realidad que ha surgido de la contemplación, pero que, a través de ella, puede llegar - palingenesia- a la perduración. Así, si Las flores de Paracelso se cerraban con la resurrección de la materia — rosa—, se abren en el poema primero - "Jardín" -, en el convencimiento de la perduración del acto contemplativo:

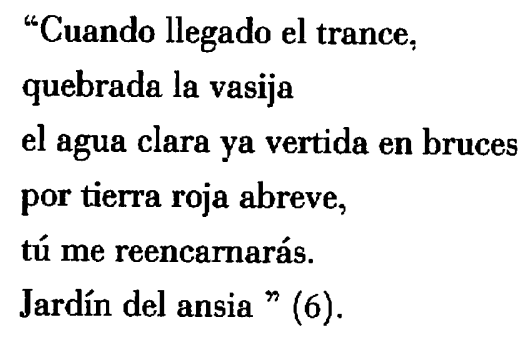

Porque lo que asciende de ese jardín no es lo vivido sino lo soñado, en en el símbolo de un aroma que perdura porque "el olor del alma / es lo que asciende", y el incendio de la flores no nos deja cenizas sino "la consumación de la fragancia". Y así, el poeta va desarrollando unos "Giclos de la palabra", "narrando lo vivido", "narrando lo soñado", "narrando lo inventado", para terminar, en el último ciclo, "narrando en la palabra", como acto final de la contemplación meditativa: "vivir soñando los inventos / de esa función vocal" (7).

Pero una vez transfigurada la realidad mediante el acto poético, acontece que esa segunda realidad habitada por palabras se nos transforma en vida. Una vida donde el sueño - lo percibido por la contemplación: deseo, memoria..., se transforma en la mas auténtica realidad. Así, ésta no es el "Retrato de una dama" (8), es decir la forma fugitiva encerrada en las líneas y colores de un medallón. Esa es la "triste realidad". La auténtica es 
"sólo aroma", porque "salvado por la atmósfera / el perfume perdura". Y el poeta se pregunta "¿Cómo así se deslía / vivir de lo soñado?", para desear categórico: "Viva soñándote".

Vivir y soñar rompen sus barreras diferenciales en el vasto dominio de la contemplación meditativa. Y en una "Visita al museo", el poeta puede llegar a fusionar la "historia" y sus "verdades" encerradas en lienzos, con la suprema "invención" que brota de aquéllos:

"Así el mundo entre lienzos sus verdades proclama

a quien la mano empuja por escribir su historia.

Tal arrebato es, que solo se medita

cuando la tierra inventas por haberla vivido.

Llevas a tu rincón lo que en ojos se queda

y pasa ahora un cortejo: criaturas han sido.

Invaden tus dominios y no sabes si sueñas

o es que soñando vistes pasando la miseria" (9).

En ese sueño el poeta recrea y vivifica lo inerte mediante la palabra. Porque "das la vida en aliento, pues calor sólo impone / quien lo real inventa / ya que lo que transcurre, fue creado por otros" (10). Y frente a "lo que transcurre", el deseo se convierte en verdad. De tal manera que "El joven vigía" (11) que da la voz de "tierra", y ésta en la realidad no existe, está gritando una más alta realidad:

"El niño no mintió; se inventó con sus ojos que era la tierra lo que deseaba".

Y ese mirar en el deseo tendrá tal poder de recreación que transfiere la verdad de lo real a la verdad de lo soñado en la meditación, porque "nunca fue realidad lo que sólo te hiere, / sino lo que te daña luego de meditado", hasta el punto de que "tus ojos, por cegados, otros mundos han visto" (12).

La realidad creada en el sueño y la meditación se transforma, en consecuencia, en algo sin límites precisos de significación, si esos límites los 
colocamos en el ámbito primero del referente real. Como ese simbólico pescador meditativo - "Pez o paloma" (13) — enfrentado con su caña al "abismo" de "algo ignoto", que poseerá el don de crear a su antojo la presa, ya que lo conseguido sólo dependerá de la fuerza del intento:

“Pero quédate extático

y medita quién fuerza.

Puede ser pez, o puede ser paloma,

si el anzuelo has lanzado a las alturas".

Igualmente, si puede su fuerza crear a su antojo una suprerrealidad, el poeta puede, también, devenir "otro distinto ser" que, habitante de la memoria y caminante de sus "sueños inventados", llegue a entrever ese "reino": "tan extraño a los otros", que en "otro tiempo" fue su posesión y hoy es solamente "perdida realidad" (14).

Creo que de esa dualidad - realidad o materia tangible y existida, frente a realidad o materia contemplada y soñada - brotan dos libros tan frecuentemente situados por la crítica en un superficial virtuosismo neobarroco, como son Las flores de Paracelso y Eros y Anteros (15). Ya he aludido en estas páginas al profundo significado del poema primero y último del poemario dedicado a la "botánica oculta" o "magia" de las flores (16). Pero, naturalmente, no a las flores - realidad referencial- sino al significado de las flores — segunda realidad-, tras la transformación meditativa de aquéllas realizada por Paracelso. Era absolutamente lógico y coherente el entusismo de Miguel Fernández ante el descubrimiento personal de la obra del científico renacentista. Cuando el humanista suizo establece científicamente la armonía entre macrocosmos y microcosmos, creo que el poeta melillense está encontrando un alma gemela. La flor —realidad primera-, y su significado y símbolo como realidad segunda: "¿Hay otra norma?", había preguntado el poeta sintetizando su proceso de creación.

O la oposición - fusión- de Eros y Anteros, los dos hijos de Venus que lucharon por la primacía en el concepto del amor que cada uno simbolizaba. Eros como deseo - "el Eros solo"- y el amor correspondi- 
do - "y el plural Anteros" (17)-, opuestos pero complementarios que, en ocasiones, se funden con la "soñada realidad" de la poética de Miguel Fernández:

"Soñada fue la escena y nunca mío ese trance, tal hora y alto nido.

Despierta: realidad, que nada es cierto" (18).

Nada es cierto en la vigilia, pero toda escena es verdadera en el deseo y el sueño. Eros se funde con Anteros. En el sueño o en la contemplación de los signos de la materia: "los signos por mí solo entendidos", del "mensaje del árbol" (19). Huellas, pisadas, objetos que devienen símbolos en la poética de Miguel Fernández — "simbolizadores" de Sultana Wahnón-, y que, en su polivalencia de significados, confieren al universo su propia multisignificación: "La idea nunca es una como el bárbaro clama, / sino que en cada cosa el mundo se infinita" (20). Objetos-símbolo que confieren, recíprocamente, en aquella segunda realidad creada, un modo de infinitud a la primera. Confiriéndola, en cierta manera, un carácter sagrado: todo símbolo es un enriquecimiento —al ampliar su significado primarioque opera sobre la segunda realidad:

"Cuando signas tu frente, es a mi corazón al que ponen un agua" (21).

Esa sacralización de la materia — que deriva de su recreación simbólica en el acto poético-, cobra en la primera época de Miguel Fernández un evidente matiz de nacimiento, germinación, fructificación de la vida. En Credo de libertad son significativamente abundantes los términos que, en el referente, poseen un valor germinativo: fermentar, grano, cosecha, espiga, levadura, semilla, polen...

"La materia sagrada del olivo

reverdece la luz del horizonte...". 
escribe en "La cosecha". Y esa materia es sagrada porque "reverdece" - recrea en intensidad - la luz. "El niño celeste" es "sagrado", cuando se convierte, "naciendo", en "materia" humana. "La madre" es, como la semilla, "materia tan pequeña que fermenta la vida" (22). Y ya en Sagrada materia, su segundo libro, "materia" se une a "levadura", "fermento" "semilla" y fructificación, o la materia "sagradamente" cobra vida en las manos del alfarero (23).

Creo que de la mano de esa inicial sacralización deviene en la poesía de Miguel Fernández esa portentosa vivificación de los objetos, que él mismo nos señaló al comentar el cuadro de Miró. Los objetos son como esos signos que él traduce como mensajes de otra realidad. Son, con frecuencia los signos-símbolo de la memoria:

"Era costumbre, luego del vals de los domingos, alimentar palomas con la miga del pan.

Descendía en volandas la bandada, nevando su alboreo en los dedos sagrados de la infancia, mientras por las rasgadas celosías del claustro, veneradas reliquias iluminan vitrinas sobre rojos damascos: medallas, rizos, cartas, la pistola y su óxido de azufre aleteando sobre las galerías del palacio; recuerdos de aquellos rostros idos; panoplias y retratos y una espineta de caoba con grabados al fuego de la llegada de Lohengrin" (24).

El "museo romántico", a través de la enumeración de sus objetos va cobrando vida, hasta significar la memoria de un tiempo pasado. O la Biografía completa de Miguel puede sintetizarse en los objetos-memoria que la sustentan: babero de párvulo, orinal de loza, misal de nácar, mosquetón, ametralladora... (25). Es una "viva recordación" que, muy proustianamente, va alzándose ante la "antigua botella con pasas y aguardiente" o 
"la colcha con flores" bordada por la madre, que son como las "labradas cancelas" que van abriendo "el sueño" ante sus pasos. $Y$ añade significativamente: "Y por el campo pasas buscando viejos símbolos", mientras, caminando entre objetos de antaño, se dispone a buscar "los datos aquéllos" que son "señales del vivir" (26).

Pero el objeto mismo puede ser algo más que esa señal del vivir: él, mismo sufre un proceso de vivificación al entrar en la segunda realidad del mundo poético de Miguel Fernández, porque "las cansadas cariátides / dejarán por la tierra su sustento, / pues la piedra es ya vida si tú unges / con tu gota de cera iluminada / el pétreo corazón" (27). La "Piedra sola" puede ser "cobijo de escorpión punzante" (28); la "Fauna doméstica" de unos "bestiarios" que son materia inerte, quedan "en libertad" en las noches del poeta, al que no "agreden" (29); la "Cerámica de Níjar", porta la cabeza del bautista que continúa sonriendo sobre ella (30); la dama del retrato abandona su puesto en él y sigue "hilando" en la "silleta de seda" del salón (31). Y el propio poeta entra en el tapiz que contempla hasta ser materia nueva de su composición:

"Bajo el tapiz

mirábame el lebrel, y le sostuve

su altanería.

Quedóse en el rosal

por no saber si es fuente lo que aflora,

o la flor es el agua que lava tus sandalias.

Silbé al halcón.

Y me llegó a la alcándara

y en la siniestra lo posé.

Tanto jardín en éxtasis:

pájaros, búhos, gacelados mármoles.

Y pétalos.

Y pétalos.

Y pétalos" (32). 
Y las bóvedas. Las emblemáticas bóvedas de Miguel Fernández, que son en "Juicio final" el ámbito de la huida; el sagrado recinto del misterio en Entretierras (33); son las bóvedas celestes que elevan la mente mientras el cuerpo duerme, en Secreto secretísimo (34). Y son en su perfección, en el cruce de sus arcos, en el equilibrio armónico de su alzada arquitectura, la suprema sacralización de la materia. Arcos que cubren, como en San Pedro de la Nave, la memoria simbólica del largo milenio que los sostiene. Bóvedas construidas con palabras, bajo cuyo amparo Miguel Fernández vio, armónica y conceptualmente, transcurrir su vida. "Estas bovedillas bajo las que veo pasar todo..." escribió amistosamente en noviembre del 92 (35). Instalado, desde ellas y no bajo ellas, en la suprema y más alta realidad de la verdad poética. 
1. Historias de suicidas. Ediciones Libertarias, Madrid, 1990, p. 190.

2. Entrevista realizada por Antonio Rodriguez Jiménez (en Suplemento Literurio Cuadernos del Sur, de Diario Córdoba, en 26 de noviembre de 1992).

3. "Sombrero con velas", en Discurso sobre el páramo, Rusadir, Málaga. 1982, p. 46.

4. De Atentado celeste. Los libros editados con anterioridad a 1983 , los cito siempre por Poesía completa, Espasa Calpe, Madrid, 1983 (p. 194).

5. "Palingenesia", último poema de Las flores de Paracelso, ed. cit., p. 301.

6. "Jardín", ed. cit. p. 281.

7. De Bóvedas, Ávila, 1992. p. 28.

8. En Tablas lunares, ed. cit. pp. 341-42.

9. De Atentado celeste, ed. cit. p. 205.

10. "Reencarnación en la palabra" de Entretierras, ed. cit., p. 278.

11. En Bóvedas, ed. cit., p. 60.

12. De Atentado celeste, ed. cit. Pp. 216-17. La indudable vinculación con Bécquer de estos presupuestos fue puesta de manifiesto por Dámaso Santos (en Pueblo, de 1 de abril de 1970), comentando Juicio final.

13. De Bóvedas, ed. cit., p. 66.

14. En Juicio final, ed. cit., p. 134.

15. Véanse las sugerentes páginas que dedica a ambos - rebatiendo la aludida interpretación-, Sultana Wahnón: El irracionalismo en la poesía de Miguel Fernández, Antonio Ubago Editor, Granada, 1983. Destaca S. Wahnón, igualmente, la acertada crítica de Rei Berroa (ínsula, núm. 410, 1981, p. 14).

16. Se señala en el citado libro de S. Wahnón la fuente concreta de la que parte el conocimiento de la obra remacentista: Paracelso. Botánica oculta. Las plantas mágicas, (México, Ed. Naturistas, 1, D.F.). que le regaló un amigo.

17. Eros y Anteros, cd. cit., p. 221.

18. fdem, p. 235.

19. "Los signos", en Tablas lunares, ed. cit., p. 356.

20. En Atentado celeste, ed. cit., p. 209.

21. En Juicio final, ed. cit., p. 145.

22. Iid. cit., pp. 48,49 y 63 .

23. En Sagrada materia, ed. cit. pp. 83 y 101.

24. De Juicio final, ed. cit. p. 116.

25. En Bóvedas, ed. cit., p. 30.

26. En Juicio final, ed. cit., pp. 135 y 140.

27. En Tierras lunares, ed. cit., p. 356 .

28. Idem, p. 346 .

29. En Bóvedas, ed.cit. p. 10.

30. Idem, p. 13.

31. "De lo pintado a lo vivo", en Bóvedas, ed. cit. p. 71.

32. En Secreto secretísimo, Torre Manrique, Madrid, 1990, p. 32.

33. Ed. cit., 131 y 276.

34. Ed. cit., p. 20.

35. Así me lo escribió en la dedicatoria de su último volumen. 